\title{
Interface Exploring of Tungsten Carbide-Stainless Steel Composites through HRTEM
}

\author{
C. M. Fernandes***, M.-G. Willinger***, M. T. Vieira** and A. M. R. Senos* \\ * CICECO, Department of Ceramics and Glass Engineering, University of Aveiro, 3810-193 Aveiro, \\ Portugal \\ ** CEMUC, Mechanical Engineering, University of Coimbra, Rua Luís Reis Santos, Pinhal de \\ Marrocos, 3030-788 Coimbra, Portugal \\ *** Fritz Haber Institute of the Max Planck Society, Department of Inorganic Chemistry, Faradayweg \\ 4-6, 14195 Berlin, Germany
}

Composites of tungsten carbide (WC) and stainless steel (SS) have been produced through an innovative powder coating technique using sputtering. These composites showed remarkable mechanical properties after vacuum sintering, in spite of significant amounts of brittle eta-phase, $(\mathrm{M}, \mathrm{W})_{6} \mathrm{C}$ [1]. The formation of eta-phase is almost inevitable, because it is thermodynamically favoured for stoichiometric C in the WC-SS system and accelerated in the SS coated WC particles, due to the reduced diffusion distances between WC and SS and the nanocrystalline character of the metallic coating [2]. Surprisingly, the mechanical properties are not seriously affected by the etaphase. In fact, relatively tough and harder materials have been obtained compared to similar compositions of WC-Co. In order to understand the microscopic reason for the reported mechanical strength, in-depth structural analysis of grain boundaries and interfaces was performed by electron microscopy.

Composites prepared from WC powders that were coated with $\sim 10$ wt. $\%$ of SS and subsequently sintered in vacuum atmosphere at $1400^{\circ} \mathrm{C}$, during $2 \mathrm{~h}$ at $20 \mathrm{~Pa}$, were analyzed. High resolution scanning and transmission electron microscopy, using a Hitachi SU 70 SEM and a JEOL 2200FS TEM, respectively, were applied in combination with energy dispersive X-ray (EDX) elemental mapping in order to study the phase and elemental composition of the sample. Preliminary results corroborate the existence of three phases in the sintered sample; WC matrix phase, Fe rich binder (Fe, $\mathrm{Cr}$, Ni as main elements) and $(\mathrm{M}, \mathrm{W})_{6} \mathrm{C}$ phase with the determined composition $\left(\mathrm{Fe}_{2.3} \mathrm{Ni}_{0.3}\right)\left(\mathrm{Cr}_{0.6} \mathrm{~W}_{2.8}\right) \mathrm{C}$ (Figure 1).

Thin layers of $\mathrm{Fe}$ rich binder phase between the $\mathrm{WC}$ and the $(\mathrm{M}, \mathrm{W})_{6} \mathrm{C}$ grains could be detected by TEM (Figure 2). The binder phase spreads as well on the $\mathrm{WC}$ as on the $(\mathrm{M}, \mathrm{W})_{6} \mathrm{C}$ surfaces with excellent interpenetration between their junctions as illustrated in Figure 2, where a continuous thin layer of Fe rich phase, less than $4 \mathrm{~nm}$, can be clearly observed at the interface of those carbide phases. The existence of ductile films along grain boundaries and phase interfaces are responsible for the good mechanical properties, namely the high toughness attained in these novel WC-SS composites. The existence of ductile films along grain boundaries and phase interface are responsible for the good mechanical properties, namely the excellent compromise between hardness and toughness attained in these WC-SS composites [1].

\section{References}

1. C.M. Fernandes et al., Ceramics International 35: 1617-23, 2009

2. C.M. Fernandes et al., Int. J Refrac. Metals \& Hard Materials 25: 310-317, 2007 


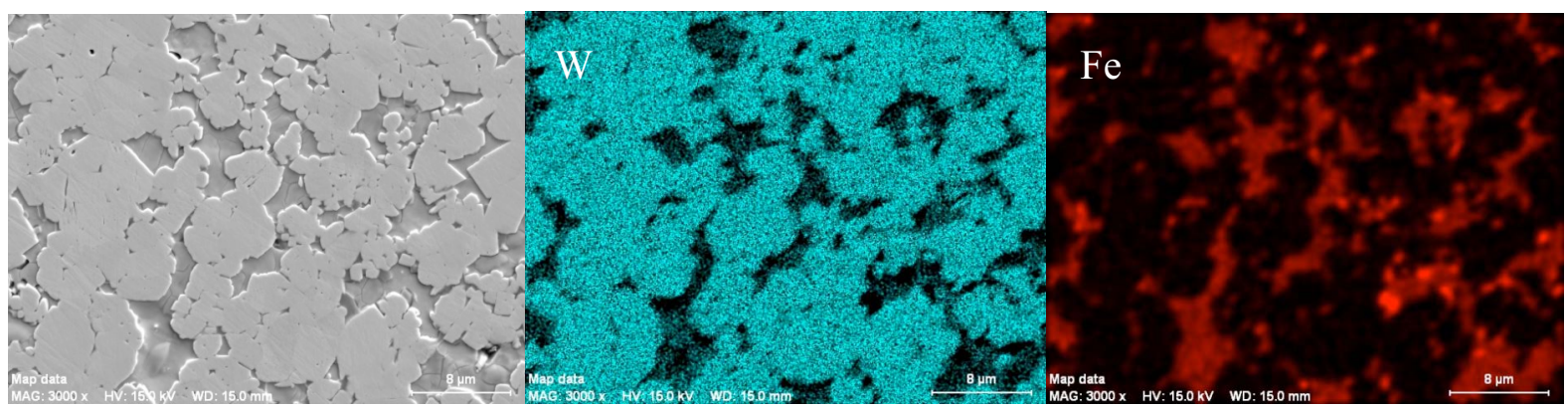

Figure 1. SEM-SE micrograph of WC-10SS sintered sample and respective X-ray maps of $\mathrm{W}$ and $\mathrm{Fe}$ elements.

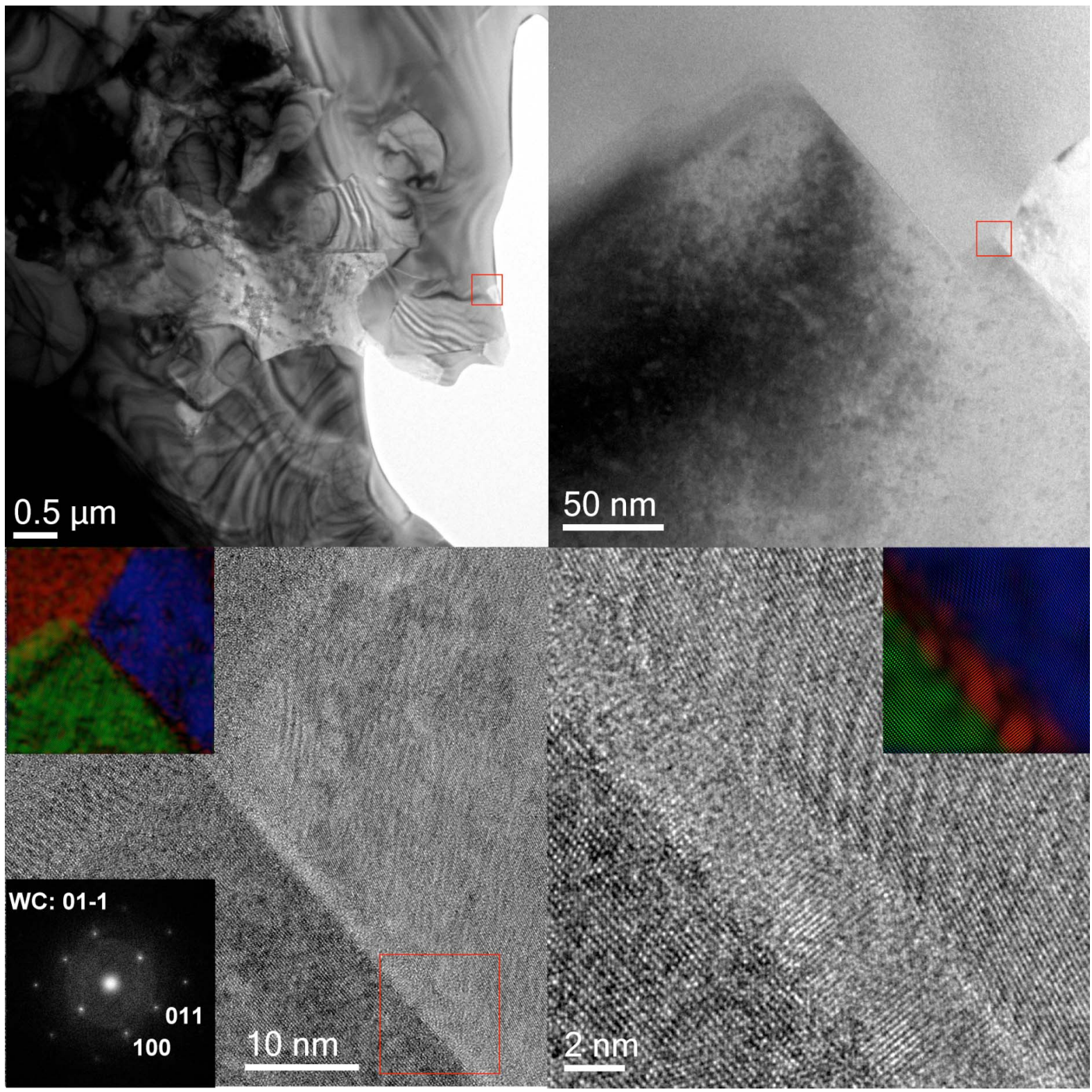

Figure 2. Overview bright field TEM images and zoomed-in views of a three phase interface. Insets in the HRTEM images show a power spectrum (FFT) corresponding to the WC phase and color coded images obtained by Fourier-filtering of the respective lattice spacings for the Fe rich binder (red), WC (green) and the (M,W)6C phase (blue). 